\title{
Changes in the Contraceptive Practice among the Women of Reproductive Age in a Selected Hospital of Dhaka City
}

\author{
Begum KS ${ }^{1}$, Alam $\mathrm{S}^{2}$, Tamanna $\mathrm{T}^{3}$
}

\begin{abstract}
Family planning is an essential tool for reducing fertility rate. An increase in contraceptive prevalence rate results in reduction of population growth, which in turn contributes significantly to the improvement of people's health. This is a cross-sectional, descriptive type of study carried out among the married women attending in the gynaeout patient department of MARKS Medical College and Hospital. This study was conducted from $1^{\text {st }}$ June 2013 to $31^{\text {st }}$ May 2014. Sample size was 250 which were selected purposively.Reproductive history was used as research instrument for data collection. Data was collected by face to face interview using structured questionnaire. Among 250 married women 156(62\%) women practicing contraceptives. Majority $45.6 \%$ of the respondents were in the age group of 25-29 yrs. Among the respondents housewives 36\%, service holder $64 \%$ and $38.4 \%$ were educated. About $42.8 \%$ respondents had 2 child followed by 3 children $36 \%$ \& only $1.6 \%$ had 4 children. $100 \%$ respondents had knowledge about oral pill and barrier method. Among the contraceptive users $35.8 \%$ respondents accepted OCP followed by barrier method 33.3\%, IUCD users were 16.7\%, 7.7\% respondents used injectables, $6.4 \%$ were natural method user and only 1.2\% used emergency pills. Maximum 59\% respondents were using contraceptives for less than one year, only $4.5 \%$ were using contraceptive of different methods for 10 years. Fertility rate, menstruation regulation is lower among servicing women. Education, empowerment and social position of women help to reduce fertility.
\end{abstract}

1. Corresponding Author:

Dr. Kazi Shahnaz Begum, MBBS, FCPS

Assistant Professor, Department of Obs\&Gynae

MARKS Medical College \& Hospital, Mirpur

2. Dr. Shah Alam, MBBS, FCPS (Gynae\&Obs), FICS Professor \& Head, Department of Obs\&Gynae MARKS Medical College Hospital, Mirpur

3. Dr. TahminaTamanna, MBBS

Assistant Registrar, Department of Obs\&Gynae MARKS Medical College Hospital, Mirpur, Dhaka.

\section{Introduction}

According to a Committee of WHO (1971), family planning refers to practices that help individuals or couples to avoid unwanted births, to bring about wanted births, to regulate the intervals between pregnancies, to control the time at which births occur in relation to the age of the parents, and to determine the number of children in the family ${ }^{1}$. Family planning not only offer contraceptive benefit, it also ensureimprovement in women's health, child health, decrease infantand maternal death, decrease population growth and ultimately enhance the socioeconomic development ${ }^{2}$. The term contraceptive include all measures, temporary or permanent, designed to prevent pregnancy due to the coital act $^{3}$. Ideal contraceptive method should fulfil the following criteriawidely acceptable, in expansible, simple to use, safe, highly effective and requiring minimal motivation, maintenance and supervision. No one single universally accetable method has yet been discovered. So there is changing trend in contraceptive practice. Fertility status(fecundity) is largely determined by age at marriage, age at $1^{\text {st }}$ child birth, birth space, and use of contraceptives. These variables are indirectly regulated by income, nutrition, housing, education and medical care of the people. There are evidenced that conditional cash transfer or improvement in socio economiccondition have unintended effect on fertility control ${ }^{4,5}$. Bangladesh's population estimated to be 146.6 million and is growing at a rate of $1.42 \%$ per annum ${ }^{6}$. Bangladesh has achieved this progress against the backdrop of low literacy rate, low status of women and low income per capita and so on. Women of reproductive age group (15-49 years) represent $46 \%$ of the total female population. Contraceptive prevalence (CPR) only $56 \%$. But total fertility rates across the countries is 2.7 (ranges from $3.3-8.7$ ) percent ${ }^{7,8,9}$. Total fertility rate in Bangladesh decline sharply over the last 37 years from 6.3 births per women in 1971-1975 to 2.7 births per women in 2004-2006 9. For reduction of total fertility rate, family planning plays crucial role ${ }^{10}$. Contraceptive prevalencerate in Bangladesh increase slowly over the last 37 years from $8 \%$ in 1975 to $56 \%$ in 2007 7. During this period improvement in maternal malnutrition (BMI less than $18.5 \mathrm{~kg} / \mathrm{sqm}$ ) $52 \%$ in $1996-$ 97 to $23.5 \%$ in $2007^{7}$. Changes in adult literacy rate $51.6 \%$ in 2004 and increase in per capita income is 
$40 \%{ }^{10}$. By studying the reproductive history, size of family, son/ daughter preference, need for another child and contraceptives prevalence can be assessed and it would be helpful informulating an intervention in order to decrease the fertility rate in Bangladesh. The present study aimed at exploring Contraceptive prevalence and related issue among service holder. The reason for non using contraceptives and the experience they gained after using different contraceptives would indicate the pathway to lower fertility rate in the society. This study would help in planning a strategy that could raise $\mathrm{CPR}$ and reduce the total fertility rate.

\section{Materials and Methods}

This is a cross-sectional, descriptive type of study carried out among the married women attending in the gynaeout patient department of MARKS Medical College and Hospital. This study was conducted from $1^{\text {st }}$ June 2013 to $31^{\text {st }}$ May 2014. Sample size was 250 which were selected purposively. Their history was taken. All patients asked for age, how long they are married, marital age of the women, age at $1^{\text {st }}$ birth, number of living children, birth space, dead children, menstruation regulation and abortion, contraceptive methods, menstrual history, desire for future pregnancy and why they need another child. 250 women (child bearing age group) were selected randomly to find out their contraceptive prevalence / fertility control. Simple random sampling technique was employed to collect data. Interviewer-administered structuredquestionnaire (Reproductive history) was used as research instrument for data collection.

\section{Results}

During the study period, 250 women enrolled in the study. Among 250 respondent 30 respondent were in 15-19 yrs age group, 66 were in 20-25 yrs, 114 were in 25-29 yrs and 40 were in $>30$ yrs age group. Among 250 respondents, 160 are service holder and 90 are housewife. Only 156 women used contractive. 100\% respondents had knowledge about oral pill and barrier method. The Majority (45.6\%) of respondents were in the age group of 25-29 yrs shows in table I.

Table I: Distribution of the respondents by age.

\begin{tabular}{lcc}
\hline Age in Years & No. of Respondents & Percentage \% \\
\hline $15-19$ & 30 & 12 \\
$20-24$ & 66 & 26.4 \\
$25-29$ & 114 & 45.6 \\
$>30$ & 40 & 16 \\
Total & 250 & 100 \\
\hline
\end{tabular}

Distribution of respondents by service in figure I below:

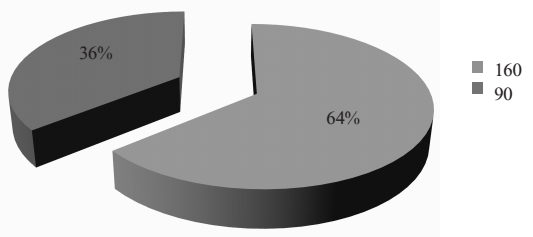

Fig- I: shows that most of the women160 (64\%) are service holder.

Distribution of respondents of educational qualification in figure II below:

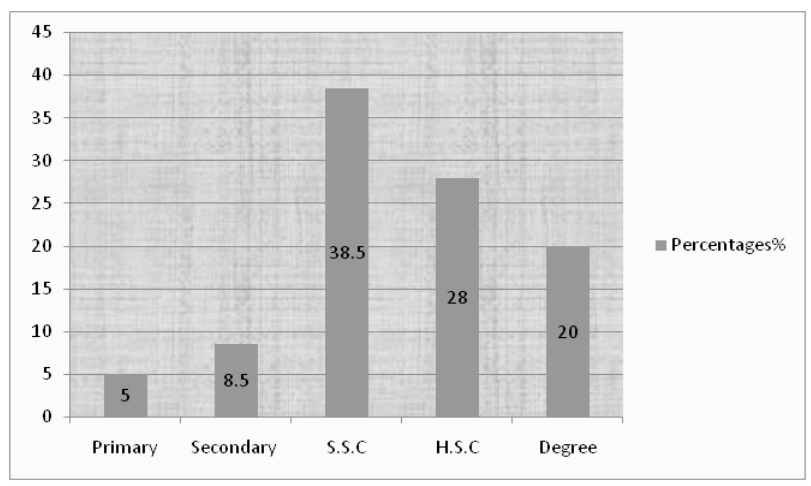

Fig- II: shows that most of the women $(38.5 \%)$ were S.S.C passed.

Distribution of the respondents regarding practice of contraceptives in figure III below:

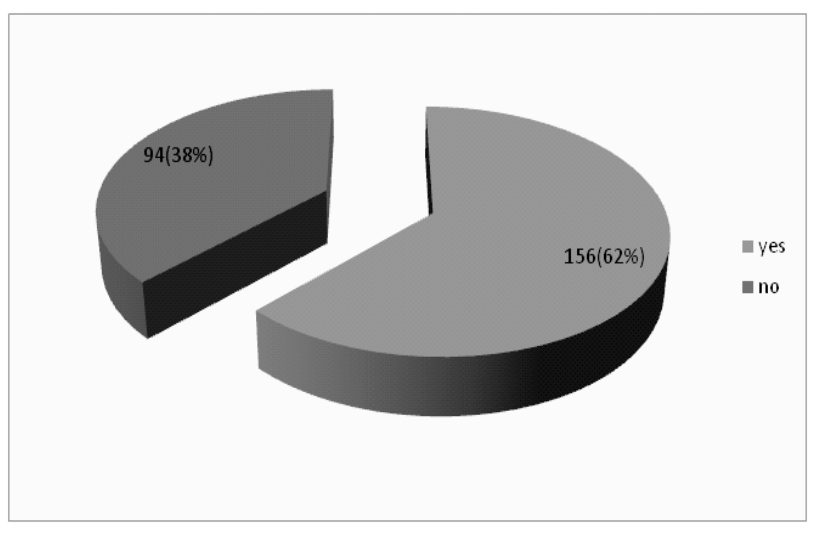

Fig: III shows that $156(62 \%)$ women used contracetive, 94(38\%) women did not use any contraceptive.

Maximum (42.8\%) respondents had 2 children followed by 3 children (36\%) \& only $1.6 \%$ had 4 children shows in table- II.

Table- II: Distribution of the respondents by number of children.

\begin{tabular}{ccccc}
\hline No.of Children & No.of Respondents & & Percentages\% \\
& & & & \\
& & Housewife & Servicing & \\
& & & Women & \\
\hline 1 & 24 & 5 & 19 & 9.6 \\
2 & 107 & 13 & 94 & 42.8 \\
3 & 90 & 50 & 40 & 36.0 \\
4 & 25 & 18 & 7 & 10.0 \\
$5-6$ & 4 & 4 & 0 & 1.6 \\
Total & 250 & 90 & 160 & 100.0 \\
\hline
\end{tabular}


Table- III: Demographic characteristics of respondents.Indicators Results

\begin{tabular}{lc}
\hline Mean age at marriage (Year) & $18.24(13-28)$ \\
\hline Mean age at $1^{\text {st }}$ birth (Year) & $21.46(14-33)$ \\
$1^{\text {st }}$ birth space (Year) & $4.29(2-10)$ \\
$2^{\text {nd }}$ birth space (Year) & $4.75(1-11)$ \\
\hline
\end{tabular}

$100 \%$ respondents had knowledge about oral pill and barrier method shows in table- IV.

Table- IV: Knowledge about types of contraceptives.

\begin{tabular}{lll}
\hline Types of contraceptive & No of Respondent & Percentage\% \\
\cline { 1 - 2 } Oral Pill & 250 & 100 \\
Injectable & 180 & 72 \\
Barrier method & 250 & 100 \\
IUCD & 166 & 66.4 \\
Other method & 70 & 28.0
\end{tabular}

(35.8\%) respondents accepted OCP followed by barrier method (33.3\%), IUCD users were $16.7 \%, 7.7 \%$ respondents used injectables, $6.4 \%$ were natural method user and only $1.2 \%$ used emergency pills shows in table-V

Table- V: Distribution of the respondents about use of different types contraceptives.

\begin{tabular}{lc|l|}
\hline Types of contraceptive & No of Respondent & Percentage\% \\
\hline Barrier method & 52 & 33.3 \\
OCP & 56 & 35.8 \\
IUCD & 26 & 16.7 \\
Injectable & 12 & 7.7 \\
Natural method & 10 & 6.4 \\
Emergency pill & 2 & 1.28 \\
Total & 156 & 100 \\
\hline
\end{tabular}

Only $4.5 \%$ respondents were using contraceptive of different methods for 10 years shows in table VI.

Table- VI: Distribution of the respondents according to duration of use of contraception.

\begin{tabular}{lll}
\hline Duration in year & No. of Respondent & Percentage $\%$ \\
\hline$<1$ & 92 & 59.0 \\
$1-5$ & 35 & 22.4 \\
$5-10$ & 22 & 14.1 \\
$>10$ & 7 & 4.5 \\
Total & 156 & 100 \\
\hline
\end{tabular}

\section{Discussion}

A woman's health is intricately entwined with her social status that in turn involves a complex set of interrelated factors. Those factors include her income, employment, education, health and fertility and society's perception of her role in the family and community 5,11 . From the study it was found that mean age at marriage is 18.24(13-28) years. It is equal with legal age of marriage ${ }^{10}$. Mean age at first birth is 21.46(18-33) years. Comparison with data from sources show that the age at which women in Bangladesh have their first child has increased steadily over time. For example, in 1975, the median age at first birth among women age 20-24 was 16.8 , rising to 18.0 in 1991- $1993,18.4$ in $1996-97$ and 18.7 in $1998-2000^{12}$. A rise in median age at first birth is typically a sign of transition to lower fertility levels ${ }^{13}$. In this study $36 \%$ women were housewife and 64\% women were service holder. We also found that most of the married women $38.4 \%$ who attended the out patient department were S.S.C passed and only $5.2 \%$ completed primary level. This indicates that women from middle and higher middle class communities want to be independent rather dependent on their husbands. It was found that maximum respondents $(42.8 \%)$ had 2 children followed by 3 children (36\%) and only $1.6 \%$ had 4 children, therefore it can be concluded that middle class or higher middle class community are concerned about their family size. This is consistent with a study by Main ${ }^{14}$. Knowledge about contraceptive is satisfactory as all the respondents $(100 \%)$ heard about this different type of contraceptive. But this study result is not similar to the the study of demography and health survey as they as they include a huge number of literate \& illiterate women of our country ${ }^{15}$. In the present study, 62 percent married women need a method of family planning. The 2001 BMMS indicates that $50 \%$ of currently married women in Bangladesh are using a method of family planning, 44\% women are using Modern method and 6\% using natural method ${ }^{12}$. In this study it is showed that 33.3 percent couple use barrier method of contraception but in Bangladesh 10.6 percent couple use barrier method of contraception 7,11 . Continued publicity against HIV and AIDS and increasing awareness of the people make use of condom more popular. In this study, 35.8\% women used OCP it is lower than national levels ${ }^{7}$. Couple have negative attitude towards pill. They think pill causes scanty menstruation, weight gain and fear of malignancy. $6.4 \%$ couple practice natural method. Natural method is not very much effective. But couples education and responsibility make the method more effective ${ }^{2,3}$. Adherence with the methods offers best result. Use of emergency contraceptive pill is also less. Only $2(1.2 \%)$ couple during the last year receive emergency contraceptive pill. Menstruation regulations (MR) are more prevalent among house wife than servicing women and fertility rate is lower among servicing women. Long term contraceptive method is not much effective for fertility reduction as well as population control because of poor acceptance. Nationally only 21.1 percent couple practice permanent method ${ }^{11}$. But in this study we did not found any couple using permanent method. At present contraception and nature alone cannot control the population in developing countries ${ }^{16}$. Most developing countries, including Bangladesh, want to reduce their fertility to replacement levels, and a recent study analyzing fertility transitions in 143 developing countries concluded that, on average, a life expectancy of 75 years and literacy near $95 \%$ are needed to approach this level ${ }^{17}$. Because it may take a long time for some countries to achieve sufficient development, policymakers need to consider other approaches for reaching this goal, such as reducing son preference and infant and child mortality, as well as improving family planning programs ${ }^{18}$. 
Family planning helps to create favorable conditions for socioeconomic development, and improve educational performance. Minimum regular income, housing, education and medical facility offer family stability and it has unintended effect on fertility. Education and social position makes one more responsible. Servicing women (empowerment) are more eager to keep family small. The fertility reducing effect of the marriage is increasing, but its effect is offsetted by the declining trend in lactational amenorrhoea period, hence the joint effect of marriage and lactational infecundability did not change much over the period. This leads to the conclusion that the future reduction of fertility in Bangladesh may be largely dependent on increased use of effective birth control methods.

\section{References}

1. Rashid KM, Khabiruddin Md.et al. Contraception; a text book of community Medicine and Public Health. $4^{\text {th }}$ edition;1995.

2. Pratapkumar, Narendramalhotra(ed) ;Contraception; Jeffcoate Principles of Gynaecology $\left(7^{\text {th }}\right.$ ed $) ; 2008$.

3. D.C.Dutta. Text book of Gynaecology.5th edition.454472.

4. GuyStecklov, Paul winters, Jessica Todd and Ferdinando Regilia. Unintended effects of poverty programmes on childbearing in less developed countries: Experimental evidence from Latin America, Population Studies. A Journal of Demography. 2007;61(2):125-140.

5. Health, Population and Development in Asia and the Pacific: Asian Development Bank, Manila. 1991:44.

6. Bangladesh Bureau Statistics Report. 2009:p-161.

7. Bangladesh Demographic and Health Survey 2010:Dhaka:84-98.
8. Begum S, Haque MM, Nasreen SA. Contraceptive Prevalence :Experience from rural Bangladesh. Mymensingh Medical Journal. July 2006;15 (2):124- 127.

9. Bangladesh fertility survey;1989.

10. George C Zaidan. The costs and benefits of family planning programs, pp 43.

11. Sample vital registration System (SVRS), BBS;2006.

12. Bangladesh maternal health service and maternal mortality survey 2001.

13. Ayesha Nasreen. Masumabegum:Contraceptive practice among the women of reproductive age. Journal of medical Science \&Research. January 2014;22(1):36.

14. Maine D. Family Planninng in Developing Countries. In:Family Planning; Its impact on the health of women and children.ColombiaUniversity:Center for Population and Family Health;1981:40-2.

15. Rahman M, D' SouzhS, Korim MR. Village characteristics and contraceptives practices. Bangladesh Fertility Research Program. Eighth contributor conference NIPORT. 1984:118-119.

16. Study on family Planning "Contraception choice" Journal of Family Planning Dhaka. March, 1997:28:37.

17. Bongaarts $\mathbf{J}$. The end of the fertility transition in the developing world, Policy Research Division Working Papers, New York: Population Council. 2002; No. 161.

18. Unnati Rani Saha and Radheshyam Bairagi. In consistencies in the Relationship between Contraceptive Use and Fertility in Bangladesh: International Family Planning Perspectives. 2007; 33(1):57. 